\title{
Culture, Network, and International Trade
}

\author{
Jae Hwa Lee*
}

\begin{abstract}
Culture and network may be interacted according to their impact on international trade, in such a way that networks alleviate the negative effect of cultural dissimilarity. This study investigates the effect of network and culture on international trade, and a possible interaction between two effects. Empirical findings from the augmented gravity model using a bilateral data set of 34 OECD countries confirm the positive effect of cultural proximity and network on trade. More importantly, the findings also reveal an interaction effect in a way that networks, such as FDI, migration and internet, play a significant role in mitigating the deterrent effect of culture dissimilarity on international trade. The internet is found to have the strongest interaction effect, followed by FDI and migration.
\end{abstract}

Keywords: Culture, Network, Trade

JEL classification: C23, F10, F43

\footnotetext{
* Department of International Trade, Dongguk University-Seoul, 3-26 Pil-Dong, Chung-Gu, Seoul, Republic of Korea. Tel.: +1 8222260 3281; fax: +1 8222260 3505. E-mail: jaehwa@dongguk.edu
} 


\section{Introduction}

Networks and culture are found to have a significant influence on international trade between countries. Network effect refers to the role of business and social networks across transnational borders in facilitating trade between countries as means of overcoming informal trade barriers (Rauch, 2001). The role of network in supporting international trade has been extensively studied in the literature (e.g., Rauch, 2001; Albuquerque et al., 2005; Rauch and Trindade, 2002; Freund and Weinhold, 2002, 2004; Greaney, 2005, 2009 Choi, 2010; Lee, 2012).

It is also acknowledged that the dissimilarity in culture between countries raises the costs of international trade, because large cultural differences make it difficult to understand, control and predict the behavior of others, thereby complicating interactions and thus, impeding the realization of business deals (Parkhe, 1991). Recent studies appear to be supportive of the impact of culture on trade. For example, Guo (2004), Tadesse and White (2008, 2010), Felbermayr and Toubal (2010), and Coughlin and Well (2011) provide evidence on the culture's role in a way that cultural dissimilarity retards trade while cultural proximity encourages trade.

Moreover, the culture and network effect may be interacted in their impact on international trade in a way that network effect across countries is likely to play a role in promoting cultural proximity and mitigating the negative effect of cultural dissimilarity: mediating effect of network on cultural influence on international trade. Despite numerous studies on the network effect and the culture effect on international trade, a possible interaction between two effects has received little attention and moreover, not yet studied in the previous study. In this context, this work goes beyond and improves upon previous findings by investigating the role of culture and networks simultaneously as well as by highlighting the extent to which networks may alleviate the negative effect of cultural dissimilarity on trade. More specifically, using the augmented gravity model for international trade with the recent bilateral data from 34 countries, this paper attempts to estimate the effect of culture and networks, such as FDI, migration and internet, as well as the possible interaction between two effects of culture and networks. The estimation concerns the hypothesis regarding the possible role of the transnational network in contributing to mitigate the negative effect of culture distance on international trade. This concern is based on the cultural convergence theory (Kincaid 2009), in which communication among members is unrestricted and the system as a whole will tend to converge over time toward a state of greater cultural uniformity. Better communication through a transnational network is likely to play an important role in promoting cultural 
proximity and mitigating the negative effect of cultural dissimilarity. As a result, it will facilitate trade across countries.

The remainder of this paper proceeds as follows. Section 2 introduces the methodology and estimation model for the impact of culture and networks on trade. Section 3 presents data sources with measure and empirical results. Section 4 concludes.

\section{Methodology}

This study uses the gravity model augmented by the variables for the effect of culture and networks. The dependent variable is the bilateral trade between two countries. As typically used in the conventional gravity equation, GDP, per capita GDP and physical distance are employed as the independent variables. In this paper, to examine the effects of culture and network, additional explanatory variables are included for culture and network variables on the right-hand side of the equation.

A simple example of cultural dissimilarity on trade is that language barriers are a significant deterrent to trade between countries. Language is an important source of identity; people may naturally prefer to trade with others who speak similar languages because they often have other things in common, such as cultural or historical ties(Lohmann, 2011). In this context, first of all, to measure the cultural proximity and dissimilarity between countries, a dummy variable for common language is constructed and used in the gravity equation in order to identify particular links between countries using common languages. Language dummy is a binary variable; if two countries $i$ and $j$ share the same main language, the variable is 1 , otherwise 0 . Next, in order to directly measure cultural dissimilarity between countries, a cultural distance index is constructed and employed in the estimation. The cultural distance index is directly constructed from Hofstede's four dimensions for culture. Cultural distance index (CDI) between country $i$ and $j$ is construed as follows:

$$
C D I_{i j}=\frac{\sum_{k=1}^{4}\left|I_{i}^{k}-I_{j}^{k}\right|}{4}
$$

where $I^{k}$ indicates $K^{t h}$ index for Hofstede's four dimensions of culture.

In addition, bilateral FDI flows, bilateral migration and the percentage of Internet users between country $i$ and $j$ are used as the proxy variables for the network effects between trading partners. In other words, bilateral FDI flows measure business network between 
countries, bilateral migration between countries measures human network across countries. And the percentage of Internet users between countries measures IT network effect across countries.

Finally, the augmented gravity equation includes the cross-product terms of culture and network effect to investigate a possible interaction between two effects such as culture and FDI, culture and migration, culture and Internet. In other words, the empirical study in this specification of the gravity model attempts to examine a possible mediating role of network effect in the impact of culture on international trade.

\subsection{Estimation Model}

First, the benchmark estimation begins with the basic gravity equation for bilateral trade between country $i$ and $j$;

$$
\log (T)_{i j}=\alpha+\beta_{1} \log (G D P)_{i j}+\beta_{2} \log (P G D P)_{i j}+\beta_{3} \log (D I S)_{i j}+\epsilon_{i j},
$$

where $T_{i j}$ is constructed as the sum of bilateral trade from country $i$ to country $j$ and that from country $j$ to country $i$; $G D P_{i j}$ is constructed by multiplying the $G D P$ of country $i$ by that of country $j$; $(P G D P)_{i j}$ is per capital GDP constructed by multiplying the per capita $G D P$ of country $i$ by that of country $j$; $D I S_{i j}$ denotes the geographical distance between country $i$ and $j$.

Second, in order to investigate the cultural effect in trade, the basic gravity equation is augmented with the variable representing cultural proximity, such as common language and cultural distance index;

$$
\begin{aligned}
\log (T)_{i j}=\alpha & +\beta_{1} \log (G D P)_{i j}+\beta_{2} \log (P G D P)_{i j}+\beta_{3} \log (D I S)_{i j} \\
& +\beta_{4}(L A N)_{i j}+\beta_{5} \log (C D I)_{i j}+\epsilon_{i j},
\end{aligned}
$$

where $L A N_{i j}$ is a dummy variable indicating common language use between two countries $i$ and $j$, and $C D I_{i j}$ indicates the cultural distance between countries $i$ and $j$.

Third, the gravity equation includes both culture and network effects simultaneously; 


$$
\begin{aligned}
\log (T)_{i j}=\alpha & +\beta_{1} \log (G D P)_{i j}+\beta_{2} \log (P G D P)_{i j}+\beta_{3} \log (D I S)_{i j} \\
& +\beta_{4}(L A N)_{i j}+\beta_{5} \log (C D I)_{i j} \\
& +\beta_{6} \log (F D I)_{i j}+\beta_{7} \log (M I G)_{i j}+\beta_{8} \log (I N T)_{i j}+\epsilon_{i j},
\end{aligned}
$$

where $F D I_{i j}$ : indicates the bilateral $F D I$ between countries $i$ and $j$ constructed by the sum of bilateral FDI flow from country $i$ to country $j$ and that from country $j$ to country $i ; M I G_{i j}$ : indicates the bilateral migration between countries $i$ and $j$ constructed by the sum of bilateral migration from country $i$ to country $j$ and that from country $j$ to country $i$; INT $T_{i j}$ indicates the IT network between country $i$ and country $j$ constructed by multiplying the percentage of internet users in country $i$ by that in country $j$.

Finally, cross-product terms of culture and network effect are included in the gravity regression in order to investigate interaction effects between culture and networks;

$$
\begin{aligned}
\log (T)_{i j}=\alpha & +\beta_{1} \log (G D P)_{i j}+\beta_{2} \log (P G D P)_{i j}+\beta_{3} \log (D I S)_{i j} \\
& +\beta_{4}(L A N)_{i j}+\beta_{5} \log (C D I)_{i j}+\beta_{6} \log (F D I)_{i j}+\beta_{7} \log (M I G)_{i j}+\beta_{8} \log (I N T)_{i j} \\
& +\beta_{9} \log (C D I)_{i j} \cdot \log (F D I)_{i j}+\beta_{10} \log (C D I)_{i j} \cdot \log (M I G)_{i j} \\
& +\beta_{11} \log (C D I)_{i j} \cdot \log (I N T)_{i j}+\epsilon_{i j},
\end{aligned}
$$

\section{Data and Results}

\subsection{Data Source and Measure}

The 2010 data for 33 OECD countries and China were used for the empirical analysis. Bilateral trade data for the countries were drawn from UN Comtrade (2012), and GDP data came from UNCTAD statistics (UNCTAD STAT). The physical distance and language data were from CEPII(Centre D'Etudes Prospectives et D'Informations Internationales). FDI and migration data were from OECD Statistics(OECD.Stat extracts). Data for internet user were from International Telecommunication Union (2012). Indices for Hofstede's four dimensions of culture were from the website for Hofstede (www.geert-hofstede.com). 


\subsection{Empirical Results}

Table 1 shows the results obtained from estimating equations (1) and (2). Columns 1-3 show three different estimations; column 1 of Table 1 presents the results from estimating the basic gravity equation, column 2 from the equation with a common language dummy variable, and column 3 from the estimation, including the effect of cultural distance. All three estimations have a good fit with adjusted R-squares of 0.8590 .868 and 0.869, respectively. The coefficient estimates for the independent variable in all three estimations were positive and statistically significant for the gravity variable and the cultural effect, which is generally consistent with those of previous findings (Tadesse and White 2008, 2010; Felbermayr and Toubal 2010; Lohmann 2011). In particular, the positive and significant coefficient for Language provides support for the common language hypothesis; country pairs with a similar official language trade more. Further, the negative and significant coefficient for Cultural Distance provides evidence for the cultural distance hypothesis; the culturally farther countries' pairs are, the less they trade.

Next, the estimation results for the interaction effects between culture and networks from the regression of equations (3) and (4) are presented in Table 2. The result from column (1) of Table 2 provides supporting evidence for network effects of three different channels; FDI, migration and internet. They are generally consistent with the previous finding in the literature (Rauch and Trindade, 2002; Freund and Weinhold, 2002, 2004;Greaney, 2005, 2009 Choi, 2010; Lee 2012).Column (2) presents the estimation results for the interaction effect. As portrayed in Table 2, positive and significant coefficients persist for all three cross-product terms of CDI-FDI, CDI-MIG and CDI-INT. Specifically, the coefficient for CDI-FDI is 0.089 ; for CDI-MIG, 0.027; and for CDI-INT, 0.529 . All these coefficients were significant at the $1 \%$ level. This result supports evidence for the role of transnational network in contributing to mitigate the negative effect of culture distance on international trade. In particular, the result indicates that, among the three channels, the internet has the strongest network effect in the interaction between culture and networks, followed by FDI and migration.

Lastly, column 3 of Table 2 reports the estimation result for equation (4), including language, culture and networks, as well as all the interaction terms. The result indicates that the coefficients for culture, network channels and all interaction terms are statistically insignificant, although they are found to be significant at the previous regression of columns (1) and (2). It is a possible symptom of a multi-collinearity problem among the interaction effect terms; the regression still maintains a relatively high adjusted R-square statistic (0.898), whereas most of the individual coefficients are insignificant (i.e., p-value is more than 0.1 . Multi-collinearity does not affect the R-square statistic; rather, it only 
affects the estimated standard errors and hence, p-values.

\section{Conclusions}

Culture and network may be interacted according to their impact on international trade. This paper examines the impact of culture and network with the interaction effect on international trade using the data set of bilateral trade between 34 OECD countries for 2010 and Hofstede's four dimensions of national culture.

The estimation results from the augmented gravity equation confirm the positive effect of cultural proximity and network on trade. More importantly, the findings also provide encouraging evidence supporting the role of FDI, migration and the internet in promoting cultural proximity and mitigating the deterring effect of cultural distance on trade. In particular, the estimated coefficients from the regression indicate that the internet is relatively more important, followed by FDI and migration among interaction effects. These results support evidence for the interaction effects between culture and network. They reveal that transnational networks, such as FDI, migration and the internet, play an important role in mitigating the deterring effect of culture distance on international trade.

This study contributes to the literature stream because it is among the first to investigate the role of networks in the interaction effect. Unlike previous research, the current research highlights the interaction effect between culture and networks as well as the role of networks by investigating whether networks may alleviate the negative effect of culture on trade.

Table 1.

Cross-country gravity regressions for trade

\begin{tabular}{c|c|c|c}
\hline & \multicolumn{3}{|c}{ Dependent variable is log Trade $_{\mathrm{ij}}$} \\
\hline & $\mathbf{( 1 )}$ & $\mathbf{( 2 )}$ & $\mathbf{( 3 )}$ \\
\hline \multirow{2}{*}{ Intercept } & $\begin{array}{c}4.017^{* * *} \\
(0.000)\end{array}$ & $\begin{array}{c}4.429^{* * *} \\
(0.000)\end{array}$ & $\begin{array}{c}4.679^{* * *} \\
(0.000)\end{array}$ \\
\hline \multirow{2}{*}{ GDP(ij) } & $\begin{array}{c}0.949^{* * *} \\
(0.000)\end{array}$ & $\begin{array}{c}0.935^{* * *} \\
(0.000)\end{array}$ & $\begin{array}{c}0.934^{* * *} \\
(0.000)\end{array}$ \\
\hline \multirow{2}{*}{ PGDP(ij) } & $-0.217^{* * *}$ & $-0.247^{* * *}$ & $-0.254^{* * *}$ \\
& $(0.000)$ & $(0.000)$ & $(0.000)$ \\
\hline
\end{tabular}




\begin{tabular}{|c|c|c|c|}
\hline & \multicolumn{3}{|c|}{ Dependent variable is $\log$ Trade $_{\mathrm{ij}}$} \\
\hline & (1) & (2) & (3) \\
\hline Geographical Distance(ij) & $\begin{array}{c}-0.987^{* * * *} \\
(0.000)\end{array}$ & $\begin{array}{c}-0.994 * * * \\
(0.000)\end{array}$ & $\begin{array}{c}-0.988^{* * *} \\
(0.000)\end{array}$ \\
\hline Language(ij) & & $\begin{array}{c}0.304^{* * *} \\
(0.000)\end{array}$ & $\begin{array}{c}0.287^{* * *} \\
(0.000)\end{array}$ \\
\hline Cultural Distance(ij) & & & $\begin{array}{c}-0.149 * * * \\
(0.000)\end{array}$ \\
\hline Observations & $\sum^{n-1=33} i=561$ & $\sum^{n-1=33} i=561$ & $\sum^{n-1=33} i=561$ \\
\hline Adjusted R-square & 0.859 & 0.868 & 0.869 \\
\hline
\end{tabular}

Notes: Trade $\mathrm{eij}_{\mathrm{ij}}$ is bilateral trade between country $i$ and $j$. The p-values are in parentheses.

$* * *$ Indicates significance at the $1 \%$ level.

Table 2.

Cross-country gravity regressions for trade with culture and networks effects

\begin{tabular}{c|c|c|c}
\hline & \multicolumn{3}{|c}{ Dependent variable is $\log$ Trade $_{\mathrm{ij}}$} \\
\hline \multirow{2}{*}{ Intercept } & $\mathbf{( 1 )}$ & $\mathbf{( 2 )}$ & $\mathbf{( 3 )}$ \\
\hline \multirow{2}{*}{ GDP(ij) } & $5.632^{* * *}$ & $8.378^{* * *}$ & $5.235^{* * *}$ \\
& $(0.000)$ & $(0.000)$ & $(0.001)$ \\
\hline \multirow{2}{*}{ PGDP(ij) } & $\begin{array}{c}0.791^{* * *} \\
(0.000)\end{array}$ & $\begin{array}{c}0.799^{* * *} \\
(0.000)\end{array}$ & $\begin{array}{c}0.792^{* * *} \\
(0.000)\end{array}$ \\
& $-0.622^{* * *}$ & $-0.571^{* * *}$ & $-0.622^{* * *}$ \\
& $(0.000)$ & $(0.000)$ & $(0.000)$ \\
\hline \multirow{2}{*}{ Geographical Distance(ij) } & $-0.792^{* * *}$ & $-0.810^{* * *}$ & $-0.792^{* * *}$ \\
& $(0.000)$ & $(0.000)$ & $(0.000)$ \\
\hline \multirow{2}{*}{ Language(ij) } & $0.201^{* * *}$ & $0.231^{* * *}$ & $0.206^{* * *}$ \\
& $(0.000)$ & $(0.000)$ & $(0.000)$ \\
\hline
\end{tabular}




\begin{tabular}{|c|c|c|c|}
\hline & \multicolumn{3}{|c|}{ Dependent variable is $\log$ Trade $_{i j}$} \\
\hline & (1) & (2) & (3) \\
\hline Cultural Distance(ij) & $\begin{array}{c}-0.148^{* * *} \\
(0.005)\end{array}$ & $\begin{array}{c}-0.236^{* * *} \\
(0.000)\end{array}$ & $\begin{array}{c}0.165 \\
(0.893)\end{array}$ \\
\hline FDI(ij) & $\begin{array}{c}0.120^{* * *} \\
(0.000)\end{array}$ & & $\begin{array}{c}0.046 \\
(0.368)\end{array}$ \\
\hline MIG(ij) & $\begin{array}{c}0.037^{* * *} \\
(0.000)\end{array}$ & & $\begin{array}{c}0.064 \\
(0.898)\end{array}$ \\
\hline INT(ij) & $\begin{array}{c}0.772 * * * \\
(0.000)\end{array}$ & & $\begin{array}{c}0.937 * * \\
(0.039)\end{array}$ \\
\hline $\mathrm{CDI}(\mathrm{ij}) \times \mathrm{FDI}(\mathrm{ij})$ & & $\begin{array}{c}0.089^{* * * *} \\
(0.000)\end{array}$ & $\begin{array}{l}0.0587 \\
(0.138)\end{array}$ \\
\hline $\mathrm{CDI}(\mathrm{ij}) \times \mathrm{MIG}(\mathrm{ij})$ & & $\begin{array}{c}0.027 * * * \\
(0.000)\end{array}$ & $\begin{array}{c}0.021 \\
(0.567)\end{array}$ \\
\hline $\mathrm{CDI}(\mathrm{ij}) \times \mathrm{INT}(\mathrm{ij})$ & & $\begin{array}{c}0.529 * * * \\
(0.000)\end{array}$ & $\begin{array}{c}0.131 \\
(0.691)\end{array}$ \\
\hline Observations & $\sum^{n-1=33} i=561$ & $\sum^{n-1=33} i=561$ & $\sum^{n-1=33} i=561$ \\
\hline Adjusted R-square & 0.899 & 0.896 & 0.898 \\
\hline
\end{tabular}

Notes: Trade $\mathrm{e}_{\mathrm{ij}}$ is bilateral trade between country $i$ and $j$. The p-values are in parentheses.

** Indicates significance at the $5 \%$ level.

*** Indicates significance at the $1 \%$ level. 


\section{References}

Albuquerque, R., Loayza, N., Serven, L. (2005) "World market integration through the lens of foreign direct investment” Journal of International Economics, 66, 267-295

Choi, C. (2010) “The effect of the Internet on service trade" Economics Letters, 109,102104

Coughlin, C. C., Wall, H.J. (2011) "Ethnic networks and trade: Intensive versus extensive margins" Economics Letters, 113, 73-75

Felbermayr, G., Toubal, F. (2010) "Cultural Proximity and Trade" European Economic Review, 54, 279-293

Freund, C. I., Weinhold, D. (2002) "The Internet and international trade in services" The American Economic Review, 92, 236-240

Freund, C. I., Weinhold, D. (2004) "The effect of the Internet on international trade" Journal of International Economics, 62, 171-189

Guo, R. (2004) "How culture influences foreign trade: evidence from the U.S. and China" Journal of Socio-Economics, 33, 785-812

Greaney, T. M. (2005) "Measuring network effects on trade: are Japanese affiliates distinctive?" Journal of the Japanese and International Economics, 19, 194-214

Greaney, T. M. (2009) "Measuring network effects on trade: a reexamination" Japan and the World Economy, 21, 219-255

Kincaid, D. L. (2009) Convergence Theory in Encyclopedia of Communication Theory (Ed), Thousand Oaks, CA: SAGE

Lee, J. (2012) "Network effects on international trade" Economics Letters, 116, 199-201

Lohmann, J. (2011) “Do language barriers affect trade?” Economics Letters, 110, 159-162 
Parkhe, A. (1991) "Inter-firm Diversity, Organizational Learning, and Long-gravityin Global Strategic Alliances” Journal of International Business Studies, 22, 579-601

Rauch, J. E. (2001) "Business and social networks in international trade" Journal of Economic Literature, 39, 1177-1203

Rauch, J. E., Trindade, V. (2002) "Ethnic Chinese networks in international trade" Review of Economics and Statistics, 84, 116-130

Tadesse, B., White, R. (2008) "Immigrants, cultural distance and U.S. state-level exports of cultural products" The North American Journal of Economics and Finance, 19, 331-348

Tadesse, B., White, R. (2010) "Cultural distance as a determinant of bilateral trade flows: do immigrants counter the effect of cultural differences?" Applied Economics Letters, 17, 147-152 